\title{
IMPLEMENTATION OF A BATTERY-FED SINGLE-PHASE INVERTER FOR A LOW POWER INDUCTION HEATING APPLICATIONS
}

\author{
Aziz Sh. Hamad ${ }^{1}$
}

1, 2) College of Engineering/Mustansiriyah Univ. Baghdad-Iraq
*Isam M. Abdulbaqi²

The available literature about this subject are patents of such device fed from the mains without design details as well [1, 2, 3]. In [4], Hanan K., study this furnace in details and simulate the proposed furnace using MATLAB Simulink.

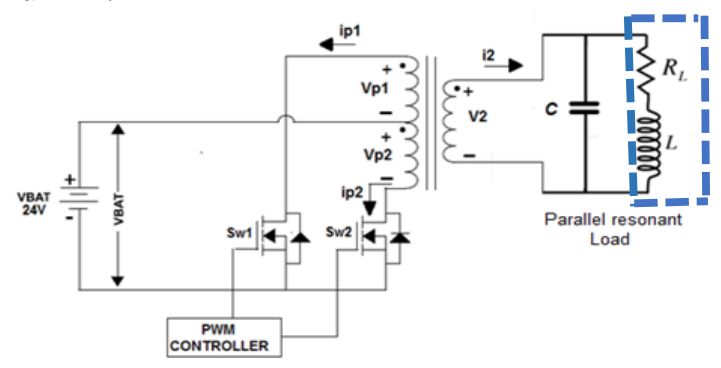

Figure 1. The proposed circuit to be implemented

In [4] a 24V battery feeding the Push-Pull inverter of a step-up transformer is proposed and simulated. The simulation results of the circuit shown in Figure. 1 reveals that (I2 $=0.44 \mathrm{~A})$ and a sinusoidal voltage appears across the tank circuit $(\mathrm{V} 2=355.24 \mathrm{~V})$, inducing a sinusoidal current in the tank circuit $\left(I_{\text {tank }}=\right.$ $1131 \mathrm{~A})$. This means that the current ratio $\left(I_{r}\right)$ of the circuit $\left(I_{r}=I_{\text {tank }} /\right.$ I2) is about (2570). This magnitude of induction coil current is able to generate a sufficient magnetic flux for the welding process by induction.

The objective of this research is to implement a prototype of the controversial circuit proposed by [4] and approve experimentally that the

*Corresponding Author: embaki56@yahoo.com 
conclusions from the simulation results are accurate.

In this work the designed ferrite transformer [5] is wounded and the IC (SG 3525 PPSB) is chosen as a PWM drive for the Push-Pull electronic switches [6]. The implemented circuit is tested by applying the output voltage of $150 \mathrm{~V}, 50 \mathrm{~Hz}$ from the proposed inverter across a tank circuit of $(1.54 \mathrm{mH})$ and $(0.33 \mu \mathrm{F})$. The obtained results approve the validity of the proposed circuit in [4].

\section{Design Implementation}

The circuit designed and simulated in [4] consists of two parts, the triggering circuit and the power circuit. The power circuit is well analyzed, while, the triggering circuit has to be discussed in this work. The most important part of the power circuit is the ferrite transformer; hence, the same design steps are implemented, and an EE ferrite core type 0P43515EC wounded with the same type and number of primary and secondary windings. The switches are MOSFETs type IRFP250 [7].

The triggering circuit is implemented using a PWM chip type SG 3525 PPSB [8] as a controller for the pulse width of the trigger fed to the MOSFETs. The properties of the IC are as follows:

- Operation voltage of (8.0V-35V).

- Separate Oscillator Sync Pin.

- Input Undervoltage Lockout.

- Adjustable Deadtime Control.

- Oscillator Range of $(100 \mathrm{~Hz}-400 \mathrm{kHz})$.

A schematic diagram of the implemented circuit is shown in Figure. 2. Two resistances are added, the first is of $10 \Omega$ connected in series with the battery and the second of $440 \Omega$ is connected in series with the tank circuit. These resistances are added for the sake of protection during the experimental test and to show the current waveforms at these branches of the circuit. Also, a tap of half the output voltage of the transformer secondary is used for testing only. Fig. 3 show the implemented prototype of Fig. 2.

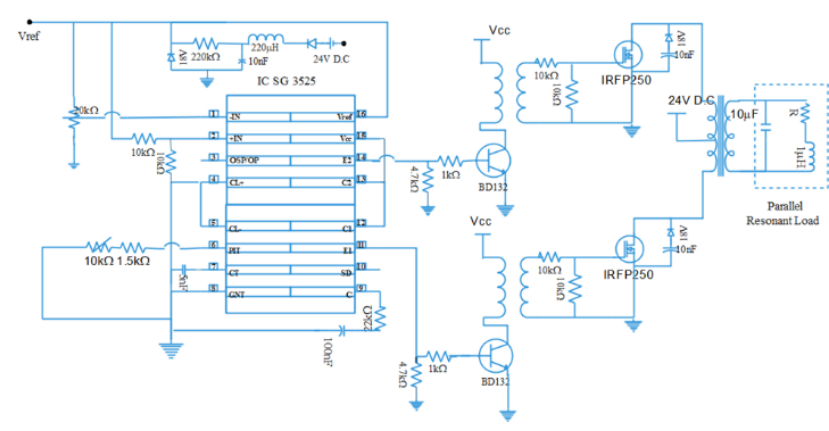

Figure 2. The implemented circuit.

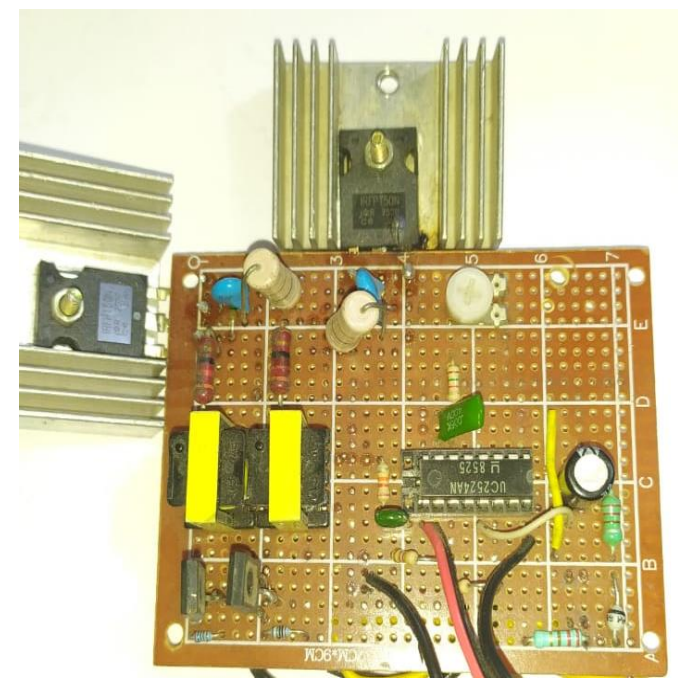

Figure 3. The implemented Push-Pull circuit

\section{Experimental Work and Discussion}

The aim of the experiments is to prove the validity of the proposed circuit. Two experiments are conducted, in the first one, the inverter loaded by a $700 \Omega$ pure resistive load, as shown in Fig. 4. The triggering pulses to the gate of the transistors shown in Fig. 5, while Fig. (6-8) show the output voltage, the voltage across the transformer primary, and the battery current consecutively. The load used in [4] is a tank circuit composed of an induction coil of $1 \mu \mathrm{H}$, and $10 \mu \mathrm{F}$ capacitor of $400 \mathrm{kVAr}$. The huge current of this circuit must be avoided in this 
step. Hence, the tank circuit used in the second experiment instead composed of a $(1.54 \mathrm{mH})$ toroidal shape, ferrite core coil (to simulate the induction coil), connected in parallel to a $(0.33 \mu \mathrm{F}, 400 \mathrm{kVAr})$ capacitor.

The following results shown in figures (9-13) are obtained in the lab. The importance of this test is that it proves the ability of the proposed power supply to feed induction furnaces in such applications.

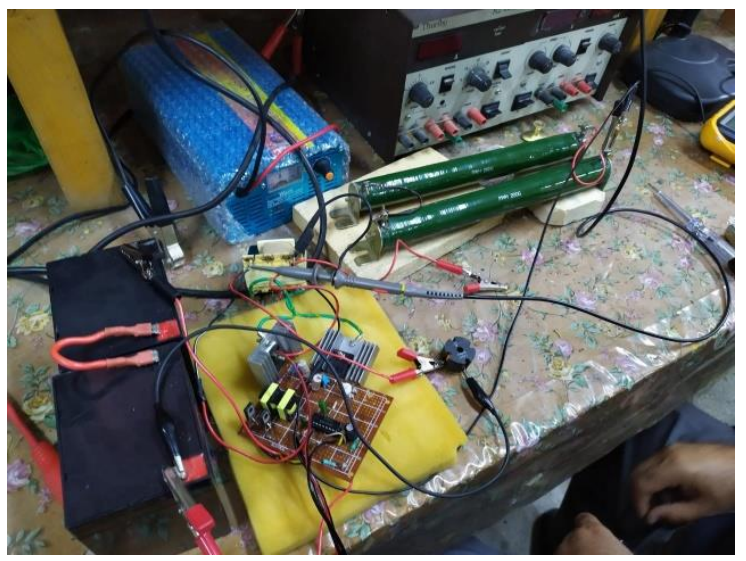

Figure 4. The test with $700 \Omega$ resistive load

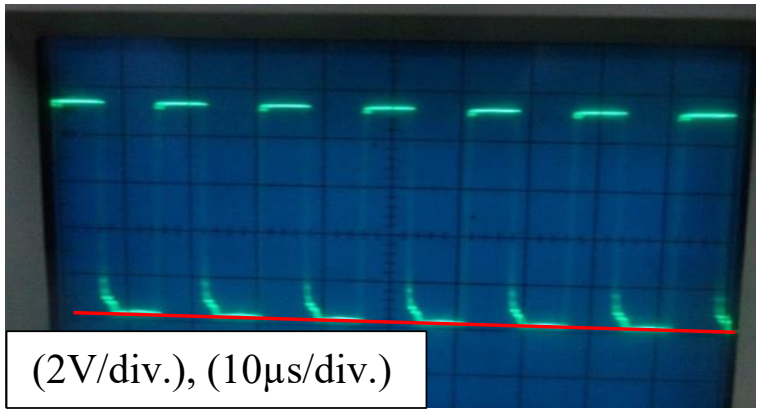

Figure 5. The triggering pulses to the gate

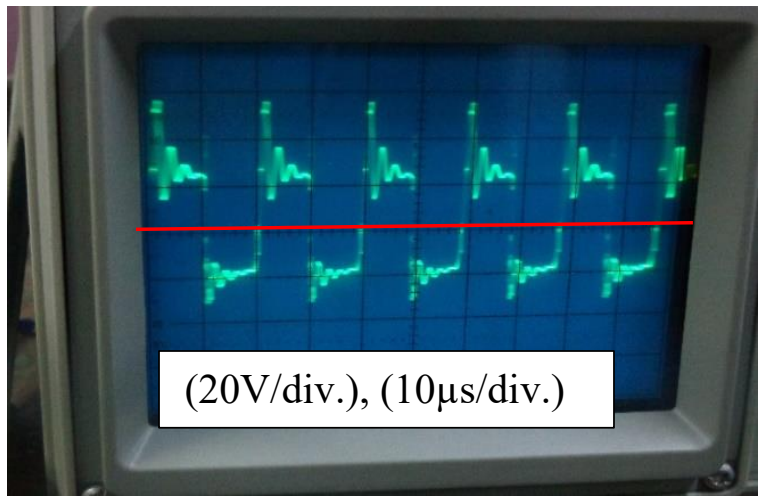

Figure 6. The primary voltage waveform
It is clear that the output voltage is a square wave of $150 \mathrm{~V}, 50 \mathrm{kHz}$ as shown in Fig. 8, which is half the output voltage of the transformer.

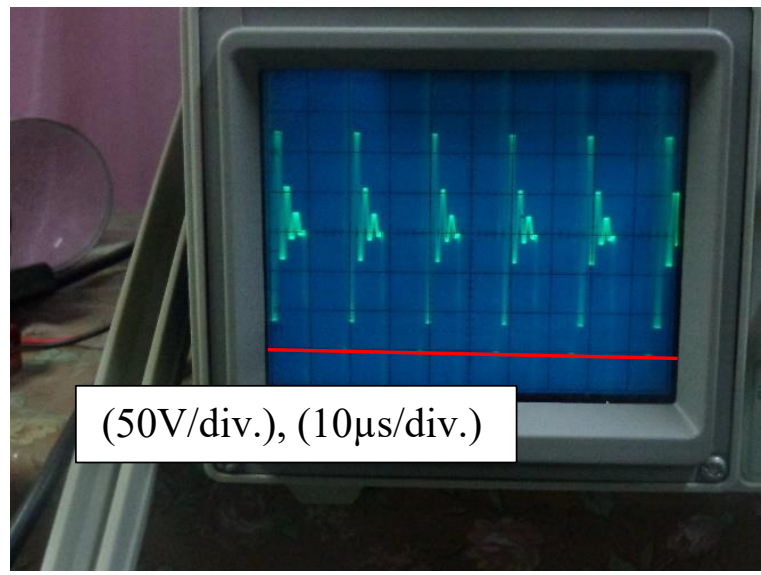

Figure 7. The output voltage waveform

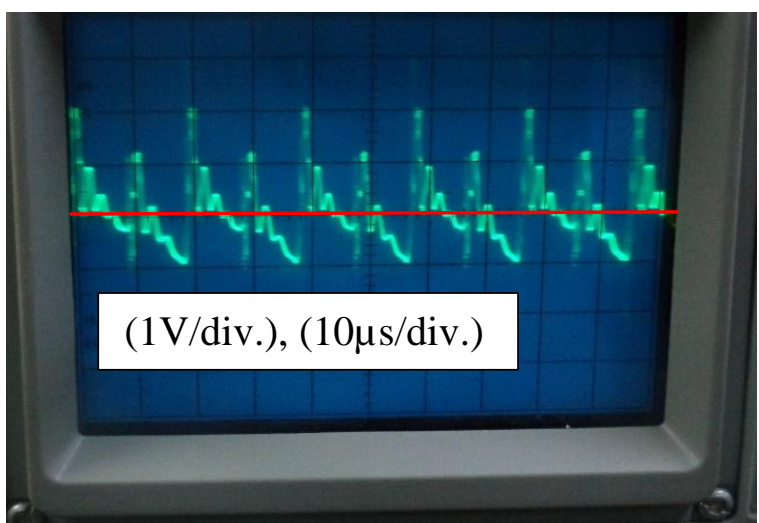

Figure 8. The current from the battery

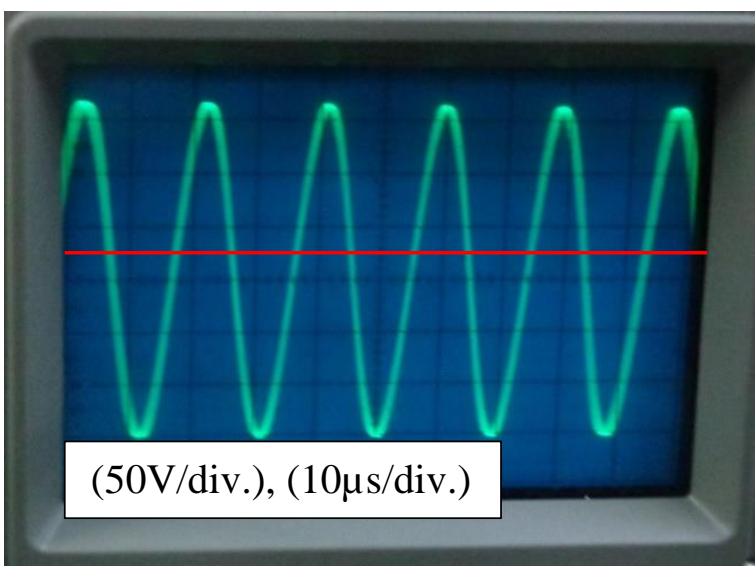

Figure 9. The voltage waveform across the tank circuit 


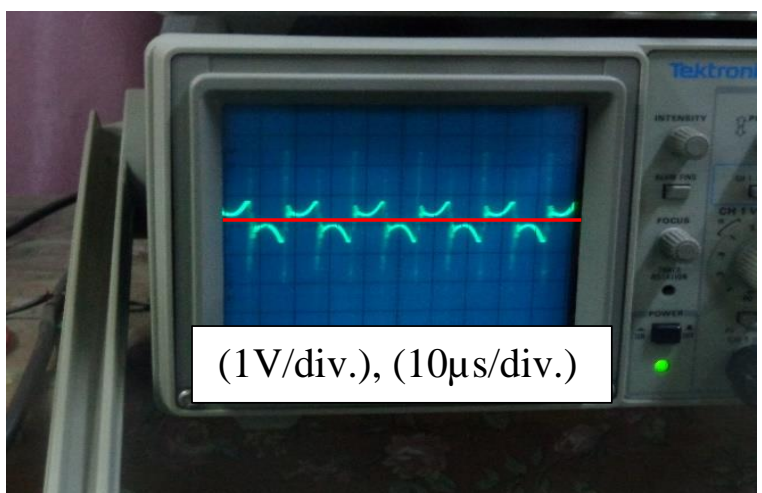

Figure 10. The voltage across the $440 \Omega$ resistor

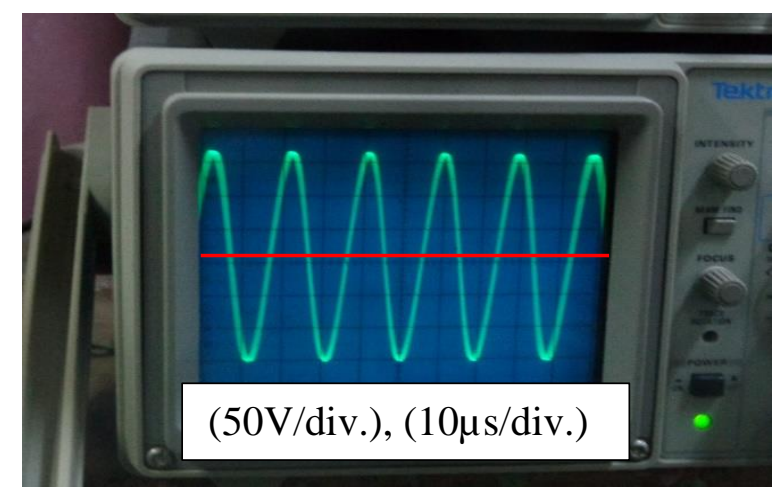

Figure 11. The secondary output voltage waveform

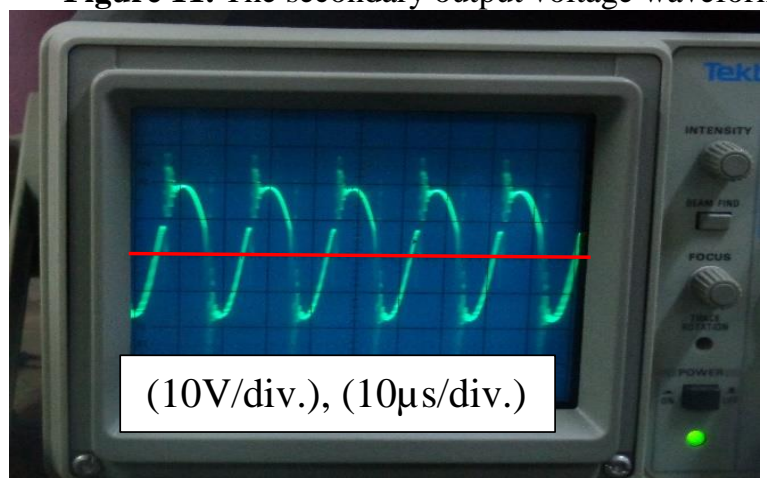

Figure 12. The voltage across the primary

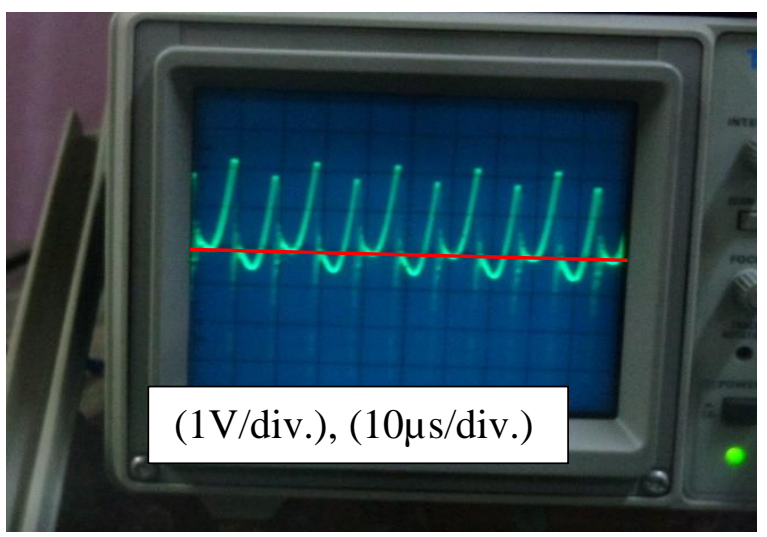

Figure 13. The voltage across the $5 \Omega$ resistance in series with battery

\section{Discussion of Results}

The experimental results obtained prove the idea adopted for such type of power supplies in induction heating. The results show that the current supplied from the push-pull transformer (I2) is $(1.5 \mathrm{~mA})$ while the tank circuit current $\left(I_{\text {tank }}\right)$ is:

$$
I_{\text {tank }}=\frac{V_{\text {tank }}}{X_{c}}
$$

$V_{\text {tank }} \equiv$ The rms value of the voltage across the tank circuit.

$I_{\text {tank }} \equiv$ The rms value of the current passing through the tank circuit.

$X_{c} \equiv$ The capacitive reactance of the parallel capacitance of the tank circuit.

Since

$$
X_{c}=\frac{1}{2 \pi f_{r} C}
$$

$f_{r} \equiv$ The resonance frequency of the tank circuit.

$C \equiv$ The capacitance of the parallel capacitance of the tank circuit.

The resonance frequency $\left(f_{r}\right)$ is $50 \mathrm{kHz}$, and the capacitance $=0.33 \mu \mathrm{F}$

$$
X_{c}=\frac{1}{2 \pi \times 50 \times 10^{3} \times 0.33 \times 10^{-6}}=9.646 \Omega
$$

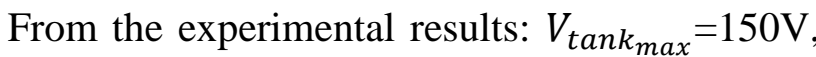
which represents the maximum value of the voltage across the tank circuit shown in Fig. 12.

Where,

$$
\begin{gathered}
V_{\text {tank }}=\frac{V_{\text {tank }_{\max }}}{\sqrt{2}}=\frac{150}{\sqrt{2}}=106 \mathrm{~V} \\
I_{\text {tank }}=\frac{106}{9.646}=11 \mathrm{~A}
\end{gathered}
$$


The current (I2) from the ferrite transformer secondary passing through the $440 \Omega$ resistance $\left(r_{s}\right)$, which is connected in series with the tank circuit can be measured by measuring the effective voltage $\left(V_{r_{s}}\right)$ across $\left(r_{s}\right)$, using a true (rms) voltmeter as follows:

$$
\mathrm{I} 2=\frac{V_{r_{s}}}{r_{s}}=\frac{0.7}{440}=1.6 \mathrm{~mA}
$$

Hence, (I2) represents the current fed by transformer secondary. From the previous calculations the current ratio $\left(I_{\text {ratio }}\right)$ between the real current and the imaginary current $\left(I_{\text {tank }}\right)$ of the tank circuit is:

$$
I_{\text {ratio }}=\frac{I_{\text {tank }}}{I 2}=\frac{11}{1.6 \times 10^{-3}}=6875
$$

Since, the apparent power supplied to the tank circuit is equal to the terminal voltage of the transformer secondary multiplied by its output current (I2), then:

$$
P_{o}=V_{\text {tank }} \times I_{s}=106 \times 0.0016=0.17 \mathrm{VA}
$$

The transformer output voltage is the same as that of the tank circuit, then the power of the tank circuit is

$$
P_{\text {tank }}=V_{\text {tank }} \times I_{\text {tank }}=106 \times 11=1166 \mathrm{VA}
$$

Hence, these results prove the validity of the theoretical results achieved using MATLAB Simulink by [4], taking into consideration the application of a real brazing load.

\section{Conclusions:}

This work leads to many conclusions, these are:

a) The proposed circuit can be used as a power supply for a portable induction welding machine.

b) The tank circuit load is more suitable than the series resonant circuit in that, the series circuit use a step down high frequency ferrite transformer[9], while the tank circuit feed the induction coil by the reactive power itself. This feature is suitable for a low weight, simple and low-price portable tool. Fig. (14) show the tank capacitor.

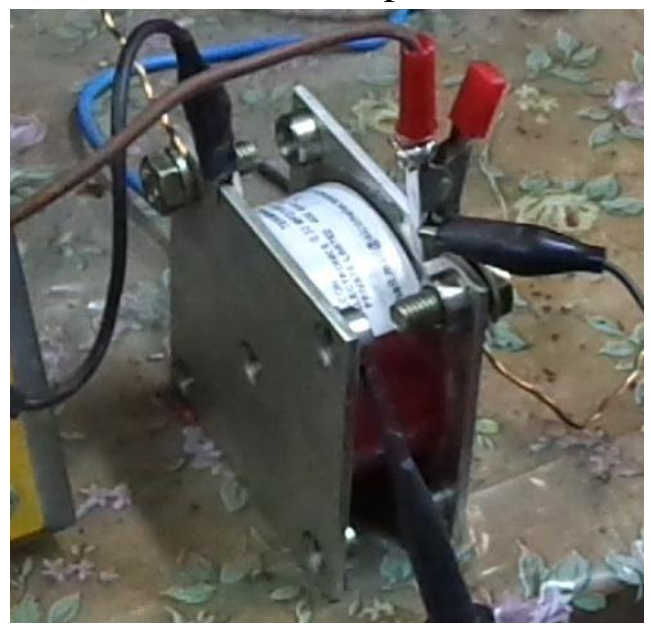

Figure 14. The tank capacitor of $0.33 \mu \mathrm{F}$

c) Since, the required capacitor for the welding machine is of $10 \mu \mathrm{F}$ capacity, then this capacitor can be achieved as two capacitors of $5 \mu \mathrm{F}$ connected in parallel as that shown in Fig. 15, since each capacitor of mass equal to $600 \mathrm{~g}$, then the an $1200 \mathrm{~g}$ will be the mass of the two capacitors.

d) The proposed induction coil for this welding machine will be as predicted by Fig. 16.

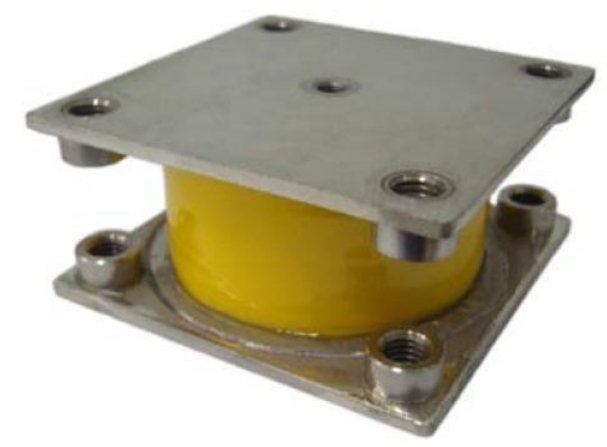

Figure 15. The $5 \mu \mathrm{F}$ capacitor

e) The portable welding machine can be built from two parts, the driving circuit and the tank circuit. These two parts connected by two thin (Litz) wires. This property furnishes a high flexibility for the users during the welding process. 


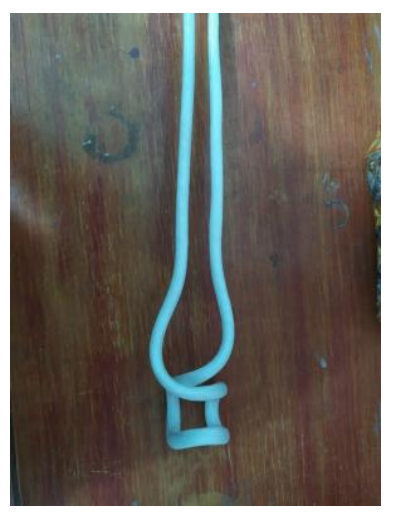

Figure 16. The proposed induction coil for copper tube brazing

\section{Acknowledgment}

Authors appreciate Mustansiriyah University for providing R\&D lab and support this work. Also, appreciate the academic support of Dr. Abdul Hassan A. Altai and Dr. Ali H. Abduljabbar. Also, we present our grateful thanks to Eng. Intisar H. Daher for her logistics support.

\section{Conflict of interest}

The authors of this article acknowledge that the publication of this article cause no conflict of interest to anybody or institution.

\section{References}

1. C. H. Henderson. (1968). "Portable Remote Induction Brazing Station with Flexible Lead". United States Patent Office No. 3,403,240.

2. John, P. Robert, C. (2006). "Portable Induction Heating Tool for Soldering Pipes having a U-Shaped Head Portion Comprising an Induction Coil”. European Patent Specification No. 1725366 B1.

3. John P. Robert C. (2007). "Induction Coil Design for Portable Induction Heating Tool”. United State Patent No. 7.202450 B2.

4. Hanan K. Abdulabbas. (2019). "Design and Analysis of a Push-Pull Inverter for
Portable Induction Welding Machine Using Battery and PV Power Source". M.Sc. Thesis, University of Technology, Iraq.

5. Wm. T. McLyman, (2004). "Transformer and Inductor Design Handbook". Third Edition, Marcel Dekker, Inc.

6. Muhammad H. Rashid, (2007) "Power Electronics: Circuits, Devices, and Applications". Third Edition, Prentice-Hall.

7. Keith Billings, Taylor Morey, (2011). "Switch Mode Power Supply Handbook". 3rd Edition, McGraw-Hill.

8. Ned Mohan, William P. Robbins, Tore M. Undeland. (2003). "Power Electronic Converters, Applications, and Design". 2nd Edition. USA.

9. Mohammad Hameed Khazaal. Isam Mahmood Abdulbaqi, Rabee' Hashim Thejel (2016). "Modeling, Design and Analysis of an Induction Heating Coil for Brazing Process Using FEM". Proc. AlSadeq International Conference on Multidisciplinary in IT and Communication Science and Applications (AIC-MITCSA). pp. 1-6. 